\title{
PENGEMBANGAN EVALUASI PEMBELAJARAN BERBASIS MULIMEDIA DENGAN FLASH, PHP, DAN MYSQL
}

\author{
Hadi Sutopo \\ Universitas Persada Indonesia YAI \\ Jalan Salemba Raya No 10 Jakarta 10440. Telepon: (021) 331525 \\ E-mail: hadi@topazart.info
}

\begin{abstract}
ABSTRAK: Computer-Based Testing (CBT) adalah ujian atau evaluasi pembelajaran yang dilakukan menggunakan komputer. Aplikasi Flash movie ini dikembangkan untuk mengerjakan soal ujian dan menyimpan nilainya dalam basisdata. Flash dikenal sebagai interface dinamis untuk aplikasi server. Aplikasi menggunakan script PHP yang berhubungan dengan Flash movie, dan melewatkan variabel dari Flash ke halaman PHP, dan sebaliknya. Dengan memanfaatkan PHP, MySQL dapat digunakan untuk menyimpan data dan diambilnya pada waktu yang lain. Menggunakan Flash sebagai front-end, data dan variabel dapat dilewatkan antara basisdata $M y S Q L$, PHP, dan Flash untuk meningkatkan fungsi halaman yang menampilkan ujian dan pengelolaan basisdata.
\end{abstract}

Kata kunci: CBT, server-side flash, interface flash, multimedia.

\begin{abstract}
Computer-Based Testing (CBT) program was launched for years to give testtakers the options of taking computerized version of test. The application which genarate academic score is developed as a server-side with Adobe Flash. Flash is well known as a powerful and dynamic front-end for the Web. However, Flash is also great interface for server-side applications. PHP can launch server-side script using Flash as a front-end and pass variables back and forth between Flash and the PHP pages. Along with PHP, $M y S Q L$ can be used to store data and later retrieve it. Using Flash as a front-end, data and variables are passed between the MySQL database, PHP, and Flash to enchance aplication's functionality in managing databases.
\end{abstract}

Keywords: CBT, Server-side Flash, Flash interface, multimedia.

\section{PENDAHULUAN}

Evaluasi pembelajaran diperlukan untuk mengukur hasil belajar seorang siswa dalam mata pelajaran tertentu. Pada umumnya evaluasi pembelajaran dilakukan secara manual, yaitu menggunakan media cetak. Evaluasi semacam ini memerlukan kehadiran siswa dan pengawas ujian pada tempat dan waktu yang ditentukan. Evaluasi pembelajaran menggunakan komputer sudah banyak dilakukan, seperti siswa mengerjakan soal dan nilai yang diperolehnya disimpan dalam basisdata. Pada umumnya aplikasi dibuat menggunakan bahasa pemrograman Pascal, Visual C, Visual Basic, Delphi, dan lainnya. Supaya tampilan menarik, aplikasi dilengkapi dengan animasi Flash. Namun, pada umumnya Flash movie hanya berfungsi sebagai pelengkap untuk memperindah tampilan. Perkembangan teknologi informasi memungkinkan siswa mengerjakan ujian pada aplikasi yang menarik menggunakan Flash, kemudian hasil nilainya disimpan dalam basisdata.

Dalam penelitian ini dilakukan pengembangan aplikasi evaluasi pembelajaran menggunakan Flash.
Pekerjaan siswa diproses oleh ActionScript yang merupakan pemrograman bagian dari Flash, dan siswa dapat mengetahui skor yang diprolehnya. Agar skor dapat disimpan dalam basisdata, diperlukan script PHP untuk menyimpan skor ke dalam basisdata MySQL di server. Dengan mengintegrasikan ActionScript pada Flash dengan script PHP, dapat diperoleh suatu aplikasi yang berbasis multimedia. Aplikasi dapat menggunakan semua objek multimedia seperti image, teks, animasi, audio, video, dan tools interaktif. Flash sebagai interface atau frontend tempat melakukan input data pada Flash movie, kemudian data dan variabel dikirimkan ke basisdata melalui PHP. Data dalam basisdata juga dapat ditampilkan kembali pada Flash movie. Dengan demikian aplikasi multimedia yang dikembangkan dengan Flash movie sebagai front-end dapat berhubungan dengan basisdata di server.

\section{Computer Based-Testing}

Komputer sebagai alat bantu pendidikan (Computer Assisted Instruction) sudah cukup dikenal, terutama di 
negara maju. Beberapa istilah lainnya yang banyak digunakan adalah Computer-Aided Learning (CAL), Computer-Based Instruction/Education (CBE), dan Computer Managed Instruction (CMI). Dalam CBE, komputer juga digunakan pada aplikasi-aplikasi bukan pembelajaran untuk menunjang sistem pendidikan, seperti mengolah data, mencatat kehadiran, dan sebagainya. Aplikasi bidang pembelajaran dengan komputer sabagai alat bantunya, di antaranya adalah Computer-Based Testing (CBT) [1].

Thompson [2] mengatakan bahwa computerbased testing merupakan perubahan baru bagi pendidik, lembaga pengujian, dan lembaga pemerintah dari ujian menggunakan kertas atau pensil ke format berbasis teknologi. Beberapa kemungkinan dapat dikembangkan menggunakan ujian berbasis komputer. Di antaranya adalah pilihan soal ujian yang dapat dilakukan oleh siswa, termasuk objek ujian yang otentik dan mendapatkan hasil ujian dengan cepat. Teknologi ini dapat membantu sekolah untuk meningkatkan dan mempersiapkan siswa pada tingkat yang lebih tinggi dengan lebih baik.

\section{Matakuliah Algoritma dan Pemrograman}

Matakuliah Algoritma adalah salah satu dari beberapa matakuliah keahlian dan keterampilan pada program studi Teknik Informatika, Sistem Informasi, dan Sistem Komputer. Matakuliah ini diberikan kepada mahasiswa pada semester pertama. Algoritma dan Pemrograman mengajarkan tentang konsep dan logika berpikir komputer, analisis dan perancangan masalah, yang kemudian dipecahkan dengan menggunakan komputer. Matakuliah ini bertujuan agar mahasiswa mampu memahami logika berpikir komputer, memahami prinsip kerja program, memahami alasan-alasan komputer dapat mengerjakan perintah-perintah yang diberikan, dan mampu menggambarkan logika jalannya program secara tertulis dengan algoritma (pseudocode) dan dilengkapi dengan diagram alir (flowchart) menggunakan suatu bahasa pemrograman tertentu seperti $\mathrm{C}$, Pascal, dan beberapa macam bahasa pemrograman tingkat tinggi lainnya. Evaluasi pembelajaran untuk mengukur hasil belajar mahasiswa dilakukan berdasarkan kuis, tugas, ujian tengah semester, dan ujian akhir semester [3].

\section{Multimedia}

Vaughan menjelaskan bahwa multimedia merupakan kombinasi antara teks, seni, suara, animasi, dan video yang disampaikan melalui komputer atau peralatan elektronik dan digital [4]. Jika elemen multimedia seperti gambar dan animasi yang dilengkapi dengan suara, video clip, dan informasi dalam bentuk teks digunakan bersama-sama, maka akan dapat memiliki makna yang jelas kepada orang yang memerlukannya. Aplikasi multimedia dibagi menjadi beberapa kategori, di antaranya yaitu presentasi bisnis, aplikasi pelatihan dan pembelajaran, promosi dan penjualan, game, dan lain-lain. Multimedia dapat membawa perubahan radikal dalam proses pembelajaran, yaitu dari pembelajaran siswa pasif menjadi model pembelajaran siswa aktif.

Informasi berbasis multimedia mempunyai beberapa keuntungan seperti disampaikan oleh Luther [5], sebagai berikut: (1) Lebih komunikatif. Informasi yang menggunakan gambar dan animasi lebih mudah dipahami oleh audiens dibandingkan informasi yang dibuat hanya dengan teks. Informasi yang diperoleh dengan membaca kadang-kadang sulit dimengerti, dan orang harus membaca berulang-ulang. Selain itu, untuk membaca suatu informasi biasanya orang harus menyediakan waktu khusus yang sulit diperoleh karena kesibukan; (2) Mudah dilakukan perubahan. Perkembangan organisasi, lingkungan, dan lain-lain mengakibatkan perkembangan informasi, sehingga informasi yang sudah ada tidak relevan lagi. Informasi perlu diperbarui sesuai dengan kebutuhan yang baru. Dalam pengembangan multimedia, semua file yang digunakan serta hasil pengembangannya disimpan dalam komputer. File tersebut dapat diubah atau ditambahkan pada suatu saat sesuai kebutuhan; dan (3) Interaktif. Penggunaan aplikasi interaktif di antaranya untuk presentasi, pemasaran, pelatihan dan lain-lain. Pengguna maupun audiens dapat interaktif sehingga keinginannya langsung bisa terpenuhi. Hal ini tidak bisa dilakukan pada informasi yang disajikan dengan cara lain seperti media cetak.

\section{METODE PENELITIAN}

Medode yang digunakan dalam penelitian ini adalah Multimedia Development Life Cycle [5] yang memiliki enam tahap yaitu, concept, design, obtainining content material, assembly, testing dan distribution. Tahapan seperti pada Gambar 1 dapat dijelaskan sebagai berikut:

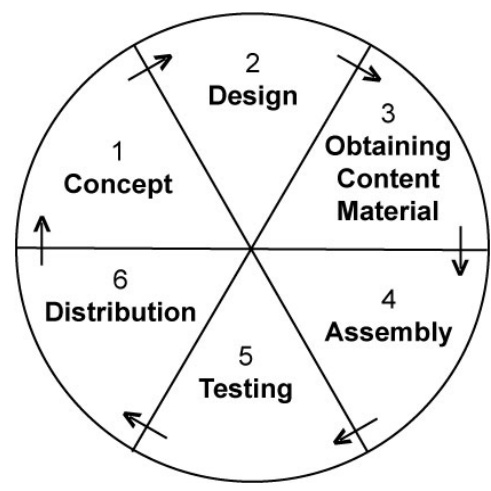

Gambar 1. Tahap pengembangan aplikasi multimedia 
1. Concept. Dalam tahap ini dilakukan identifikasi perkiraan kebutuhan yang dihasilkan dari pengamatan pada penelitian, serta pembuatan materi untuk evaluasi matakuliah Algoritma dan Pemrograman. Disamping itu dilakukan analisis mengenai teknologi, ragam multimedia, dan penyimpanan nilai hasil belajar mahasiswa.

2. Design. Dalam tahap ini dilakukan pembuatan desain visual tampilan, interface, storyboard, dan struktur navigasi. Desain multimedia memerlukan pemetaan struktur navigasi (navigation structure atau site map) yang menggambarkan hubungan antara beberapa konten dan membantu mengorganisasi konten dengan pesan. Di samping itu, pada tahap ini juga dibuat perancangan algoritma untuk aplikasi evaluasi pembelajaran.

3. Obtaining content material. Pada tahap ini dilakukan pengumpulan bahan seperti image, animasi, audio dan video. Bahan yang diperlukan dapat diperoleh dari perpustakaan, atau pembuatan khusus untuk aplikasi ini.

4. Assembly. Tahap assembly merupakan tahap dimana seluruh objek multimedia dibuat berdasarkan storyboard dan struktur navigasi yang berasal dari tahap design. Dalam tahap ini dilakukan pembuatan ilustrasi, audio dan video, serta pemrograman.

5. Testing. Tahap testing (uji coba) dilakukan setelah selesai tahap pembuatan. Pertama-tama dilakukan uji coba secara modular untuk memastikan apakah hasilnya seperti yang diinginkan. Selanjutnya dilakukan uji coba untuk evaluasi matakuliah yang melibatkan mahasiswa dan dosen. Dari hasil uji coba dilakukan perbaikan sesuai dengan saran masukan dari mahasiswa dan dosen. Dari hasil perbaikan dilakukan uji coba lagi agar meningkatkan kinerja aplikasi sehingga memenuhi kebutuhan untuk evaluasi hasil belajar mahasiswa.

6. Distribution. Setelah uji coba yang mungkin perlu dilakukan beberapa kali, dalam tahap ini dilakukan pembuatan master file, pedoman penggunaan aplikasi, serta dokumentasi sistem.

\section{HASIL PENELITIAN DAN PEMBAHASAN}

Hasil penilitian pengembangan aplikasi evaluasi hasil pembelajaran mata kuliah Algoritma dan Pemrograman dapat dirinci sebagai berikut:

\section{Concept}

Aplikasi evaluasi pembelajaran yang dikembangkan dengan Adobe Flash akan digunakan untuk mendapatkan hasil belajar mahasiswa. Pelaksanaan evaluasi dilakukan dalam laboratorium komputer, sehingga tiap mahasiswa dapat mengerjakan soal yang terdapat dalam aplikasi. Soal yang dikerjakan sebanyak 20, dan harus diselesaikan dalam waktu 10 menit. Mahasiswa dapat melihat langsung nilai yang diperolehnya, dan nilai tersebut disimpan ke dalam basisdata. Program dibuat sehingga dapat menampilkan soal secara acak, sehingga soal antara mahasiswa satu dan lainnya berbeda.

Flash movie tidak hanya digunakan untuk pembuatan animasi agar tampilan lebih menarik, tetapi juga bisa digunakan untuk menangani clientside [6]. Kemampuan Flash tidak hanya menangani client-side, tetapi dapat juga digunakan untuk aplikasi yang berhubungan dengan pengolahan server-side. Flash movie sebagai interface tempat pengguna melakukan sesuatu untuk pemrosesan di server, kemudian hasilnya ditampilkan kembali pada Flash movie. Flash sebagai interface suatu aplikasi yang berhubungan dengan basisdata membuat tampilan lebih menarik, sesuai dengan animasi yang digunakannya. Pada saat ini belum banyak yang menggunakan Flash movie untuk penanganan serverside, karena anggapan pada umumnya yang mengatakan bahwa Flash hanya dapat digunakan untuk membuat animasi serta memperindah tampilan. Dengan kreativitas, pemahaman ActionScript, dan script lain seperti PHP akan menghasilkan tampilan yang dinamis dan menarik.

Pada client-side, proses dilakukan pada browser, yang biasanya diperlukan untuk hal-hal yang berhubungan dengan interaksi pengguna. Pada umumnya client-side digunakan untuk pengolahan data yang relatif sedikit. Proses dilakukan pada browser dengan script seperti JavaScript, ActionScript, dan lain-lain. Beberapa contoh penggunaan client-side Flash adalah: (1) Aplikasi perhitungan, seperti menghitung angsuran rumah dengan memperhatikan bunga bank sesuai perhitungan real estate; (2) Aplikasi game; dan (3) Aplikasi computer-based testing. Server-side digunakan untuk memproses semua yang berhubungan dengan server, seperti guest book, pooling, feedback, dan aplikasi basisdata lainnya. Pada server-side, proses dilakukan di server, sedangkan client hanya menerima hasil dalam bentuk HTML. Contoh penggunaan server-side antara lain adalah registrasi pengguna, konfirmasi password, dan penambahan record dalam basisdata.

Gambar 2 menunjukkan hubungan dasar antara Flash, PHP, dan basisdata. Untuk membaca data dari basisdata, Flash mengirimkan perintah loadVariables Num() ke script PHP. Script PHP membuka basisdata dan mengambil data dari satu atau lebih tabel. Kemudian data dikonversi ke format yang dapat dibaca oleh Flash, menempatkan pada variabel, dan selanjutnya dikirimkan kembali ke Flash. Setelah data 
ditambahkan ke dalam basisdata, informasi dimasukkan ke dalam field teks dari Flash atau objek output yang lain (button atau movie clip). Script PHP membuka basisdata yang dibuat dengan MySQL dan kemudian mengakses tabel di dalamnya. Dengan menggunakan script PHP, data dari Flash disisipkan ke dalam basisdata. Sementara itu, Flash movie berfungsi sebagai interface untuk script PHP, menggantikan dokumen HTML di mana script PHP berada di dalamnya.

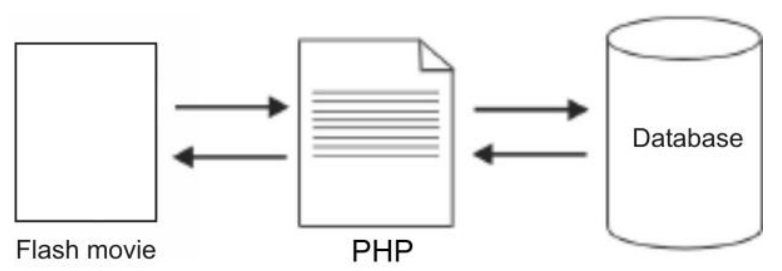

Gambar 2. Mekanisme pengiriman data antara Flash, ASP, dan basisdata di server

\section{Design}

Dalam tahap ini dilakukan perancangan dengan membuat stoyboard dan struktur navigasi, Sebagian besar peta navigasi dalam multimedia terbagi menjadi empat macam [4], yaitu: (1) Linear, informasi berjalan secara berurutan dari frame satu ke frame lain, atau dari tampilan satu ke tampilan berikutnya. Pengguna tidak dapat mengakses tampilan yang dikehendaki atau meloncat ke tampilan yang dibutuhkan; (2) Hierarchical, pengguna dapat membuat navigasi dengan percabangan sebagai struktur pohon. Struktur navigasi ini sesuai untuk aplikasi untuk kebutuhan organisasi;(3) Nonlinear, pengguna dapat membuat navigasi dengan bebas dalam seluruh tampilan; (4) Composite, penguna dapat membuat navigasi bebas dan juga dapat memiliki struktur pohon. Namun, kadang-kadang dengan percabangan yang terlalu kompleks dapat membingungkan untuk kembali ke tampilan sebelumnya.

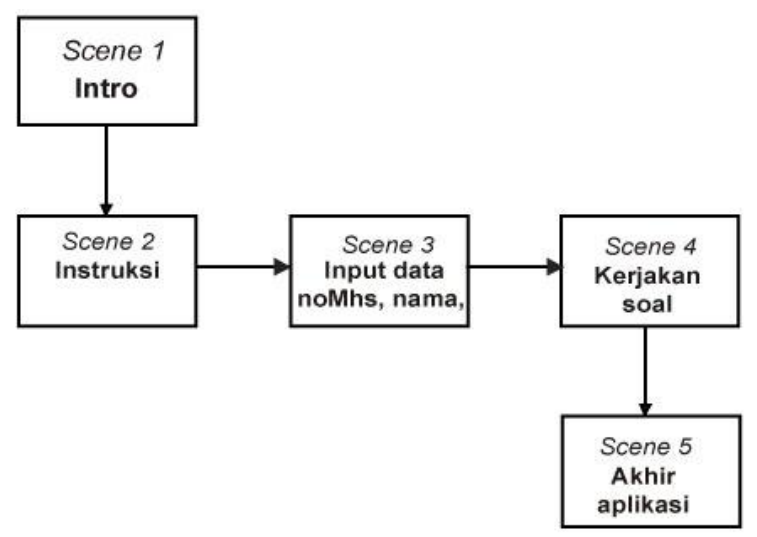

Gambar 3. Struktur navigasi
Secara garis besar, cara kerja sistem aplikasi yang dikembangkan dapat dilihat dalam struktur navigasi pada Gambar 3. Modul "Kerjakan Soal" pada Scene 4 secara rinci dapat dilihat pada Gambar 4. Setelah data dimasukkan melalui keyboard, selanjutnya pengguna dapat mulai mengerjakan soal dengan mengklik suatu button. Pengguna dapat menentukan satu dari beberapa macam pilihan jawaban yang tersedia, selanjutnya muncul skor yang menunjukkan 5 jika benar, dan 0 jika salah. Setelah menjawab soal tersebut, muncul soal berikutnya untuk dikerjakan. Demikian berulang-ulang sampai waktu yang disediakan pada timer dilampaui. Jika waktu pada timer dilampaui, secara otomatis skor disimpan dan aplikasi kembali ke tampilan awal. Namun, jika waktu pada timer belum dilampaui, pengguna dapat menyelesaikan aplikasi dengan menekan button Submit.

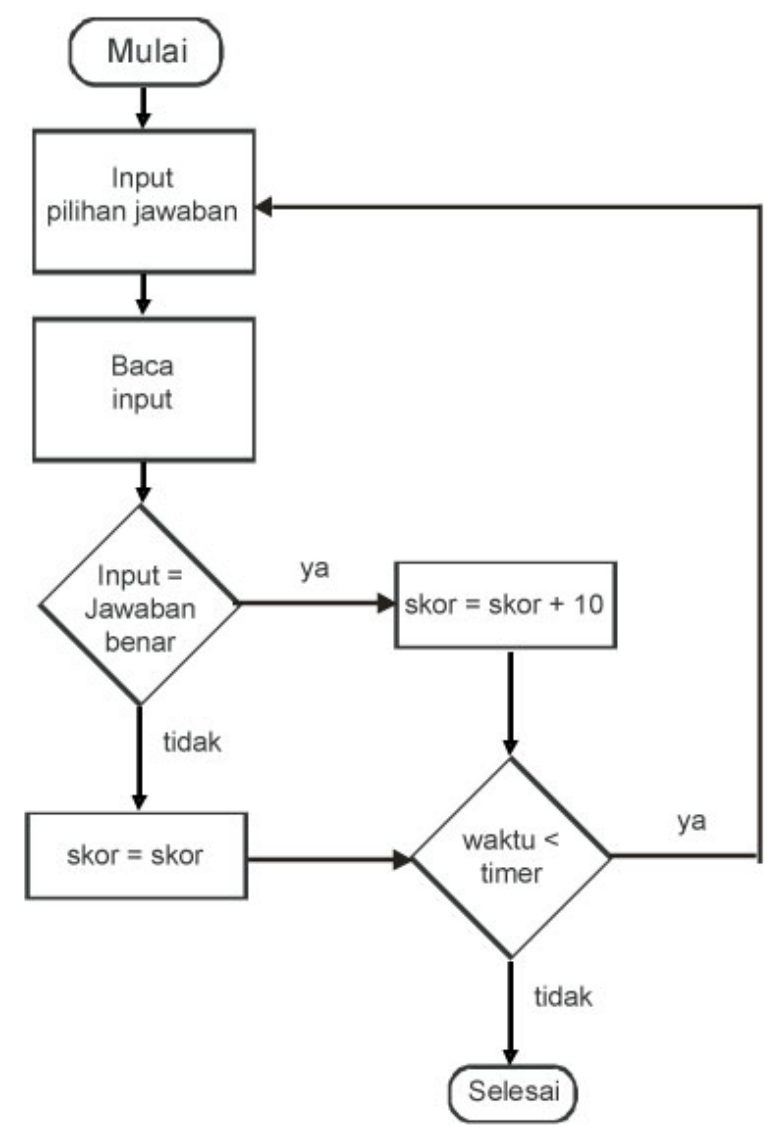

Gambar 4. Diagram alir pada Scene 3 Kerjakan Soal

Pada pembuatan aplikasi evaluasi pembelajaran, salah satu yang harus dikerjakan dan dipikirkan adalah metode penyimpanan pertanyaan dan jawaban. Pertanyaan harus mudah diubah dengan pertanyaan baru, dan pertanyaan tersebut dibuat dalam format yang dapat dikerjakan pada sistem lain. Pertanyaan untuk evaluasi pembelajaran dapat disimpan dalam 
tiga macam cara [7], yaitu; (1) Pertanyaan ditulis dalam variabel ActionScript, dan disimpan sebagai bagian dari Flash movie; (2) Pertanyaan disimpan dalam file text eksternal, di mana file tersebut dapat diload ke dalam movie; dan (3) Pertanyaan disimpan dalam basisdata, di mana dapat dilakukan query dan di-load ke dalam movie.

Dalam aplikasi ini, pertanyaan disimpan dalam file text eksternal, sehingga perubahan pertanyaan dapat dilakukan lebih mudah dibandingkan dengan penyimpanan sebagai variabel ActionScript dalam Flash movie. Perubahan pertanyaan dapat dilakukan tanpa membuka kembali source code pada Flash. Cara demikian memiliki kelemahan, karena seseorang dapat mengubah isi file dengan mudah. Disamping itu, dalam format tersebut seseorang dapat dengan mudah melihat isi file text, dan melihat jawaban yang benar untuk setiap pertanyaan.

\section{Obtaining Contain Material}

Dalam tahap ini dikumpulkan bahan-bahan seperti audio musik dan efek seperti tepuk tangan, serta image untuk background. Pekerjaan ini dapat dilakukan berama-sama dengan tahap Assembly.

\section{Assembly}

Pada penelitian ini dikembangkan aplikasi menggunakan Adobe Flash dengan PHP dan basisdata MySQL, serta pembuatan file text unuk menyimpan pertanyaan dan jawaban. Pertama-tama dibuat tabel dalam basisdata MySQL. Dalam basisdata MySQL, dibuat tabel "evaluasi" dengan empat field yang diperlukan, yaitu noMhs, nama, numq, dan score. Untuk memasukkan data dan menambahkan record dalam basisdata tersebut, perlu dibuat file PHP.

Script "addrecord.php" yang digunakan untuk menambahkan record ke dalam basisdata dapat dituliskan sebagai berikut:

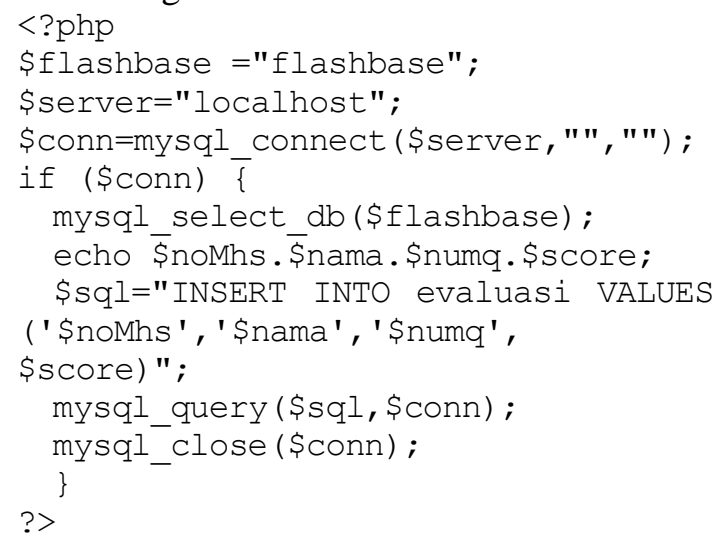

Dalam aplikasi ini dibuat tigapuluh file text untuk pertanyaan dan jawaban, sedangkan yang akan ditampilkan hanya duapuluh secara acak. File text untuk pertanyaan dan jawaban dibuat, seperti contoh salah satu file dengan nama "q1.txt" berisi data sebagai berikut:

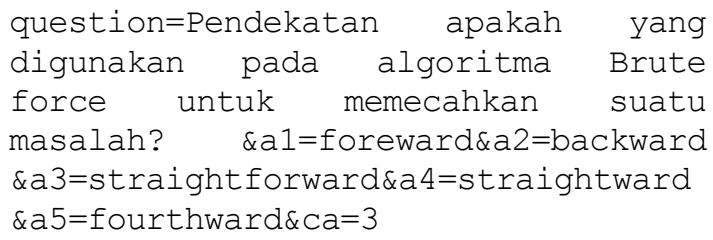

Tampilan Flash movie untuk menambahkan record ke dalam basisdata dapat dibuat seperti pada Gambar 5. Setelah mengisi data selengkapnya, button Submit ditekan. Sript pada button Submit adalah sebagai sebagai berikut:
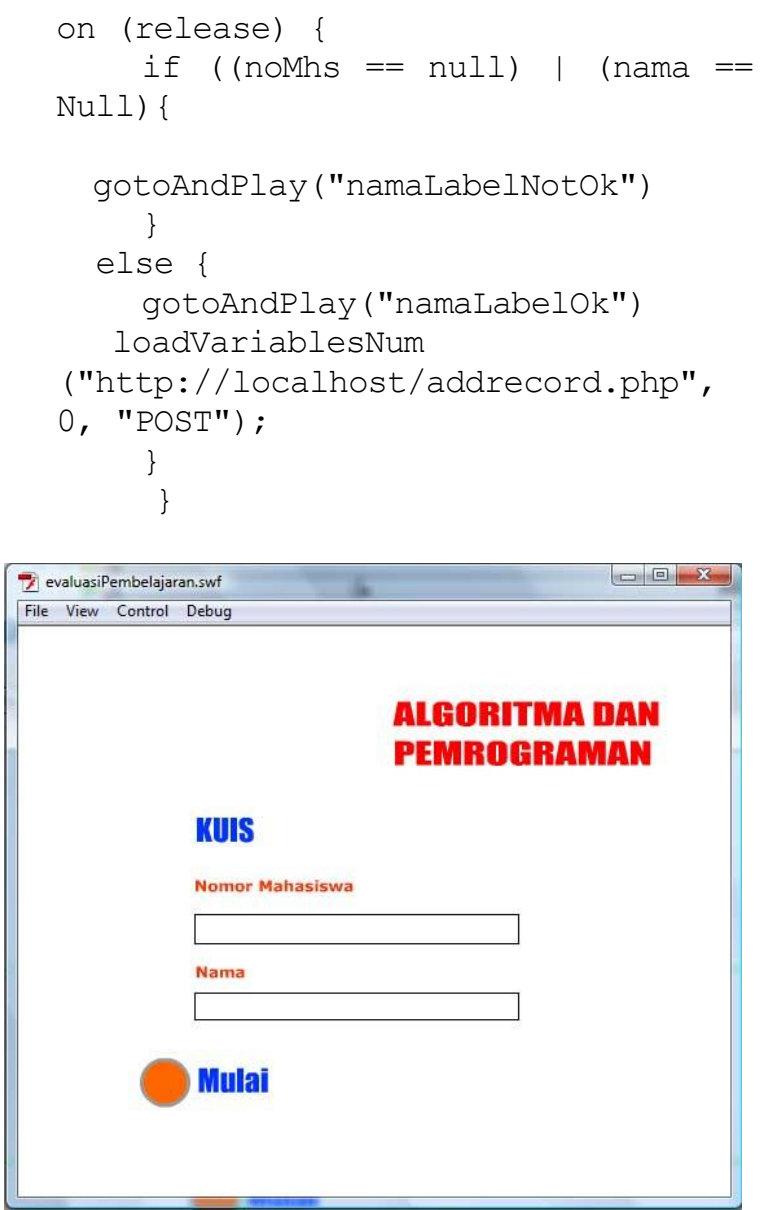

Gambar 5. Layout pada tampilan pendaftaran peserta

Tampilan selanjutnya adalah soal pertama, yaitu pertanyaan dengan lima pilihan jawaban. Jika pilihan benar maka pada field nilai akan muncul angka 5, tetapi 0 jika salah, seperti pada Gambar 6. Dengan mengklik button Lanjut akan muncul pertanyaan kedua yang berulang-ulang hingga waktu pada timer melampaui batas yang ditentukan. 
Karena terdapat tigapuluh file text untuk pertanyaan dan jawaban, sedangkan yang akan ditampilkan hanya duapuluh secara acak, maka dibuat array dari kumpulan file tersebut, dengan cara membuat script pada frame dokumen Flash sebagai berikut:
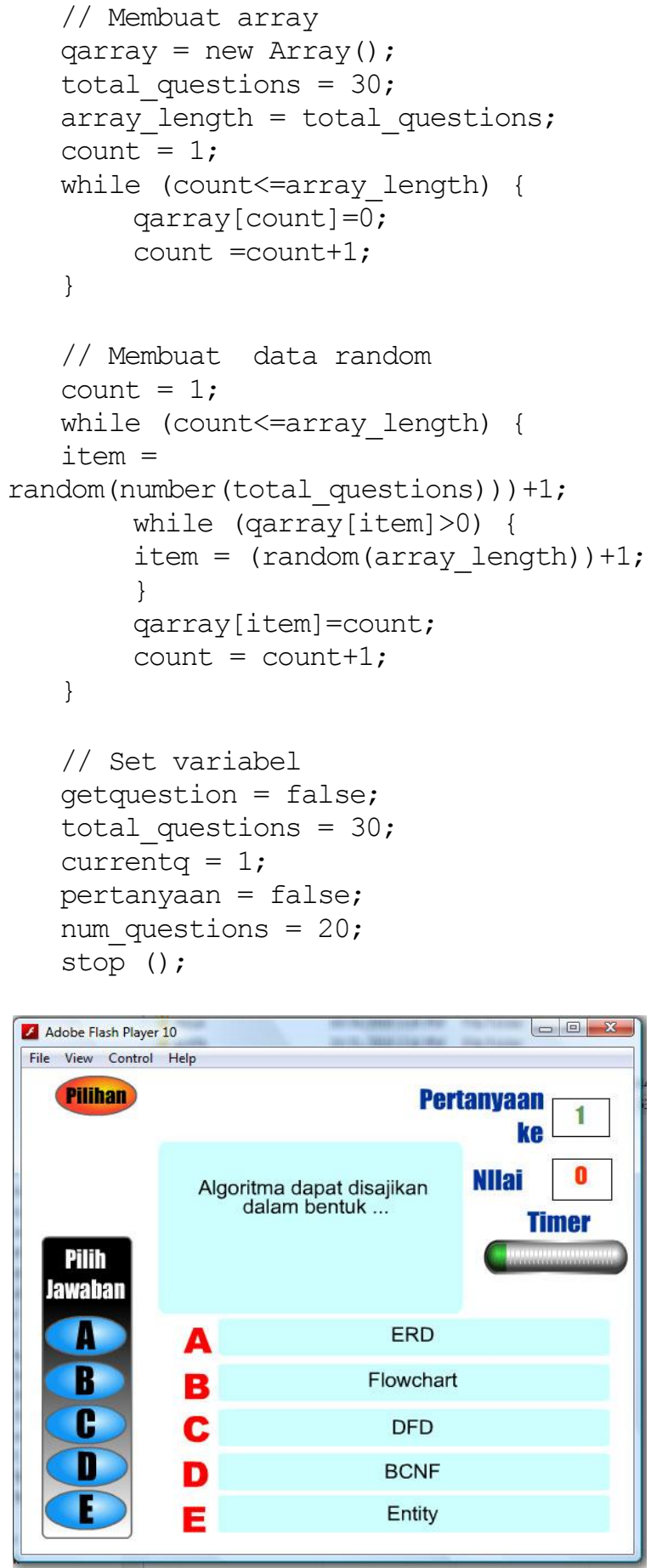

Gambar 6. Tampilan pertanyaan dan jawaban pada Flash movie

\section{Testing}

Testing (uji coba) dilakukan dua kali, melibatkan 21 mahasiswa dan seorang dosen pada Program Studi
Teknik Informatika Sekolah Tinggi Teknik Multimedia Cendekia Abditama, Tangerang. Aplikasi dijalankan pada komputer di laboratorium komputer dengan server untuk menyimpan basisdata MySQL.

Dalam uji coba pertama yang melibatkan 21 orang mahasiswa, pertama-tama mahasiswa memasukkan data nomor mahasiswa dan nama, kemudian mengerjakan soal sampai waktu pada timer. Selama mengerjakan soal, mahasiswa dapat melihat informasi berapa skor yang diperolehnya, serta nomor soal yang dikerjakan. Jika waktu pada timer dilampaui, secara otomatis data disimpan dalam basisdata, seperti dapat dilihat pada Gambar 7. Uji coba pertama memperlihatkan bahwa tidak seorangpun yang dapat menyelesaikan seluruh soal, paling banyak hanya menyelesaikan 12 soal, sehingga nilai rata-rata yang diperoleh mahasiswa adalah 31.9. Hal ini memperlihatkan bahwa waktu 10 menit pada timer untuk mengerjakan 20 soal terlalu singkat. Dosen yang mengampu matakuliah Algoritma dan Pemrograman memberikan saran agar diberikan waktu cukup bagi mahasiswa untuk berpikir dalam mengerjakan soal.

\section{Database flashbase - table evaluasi}

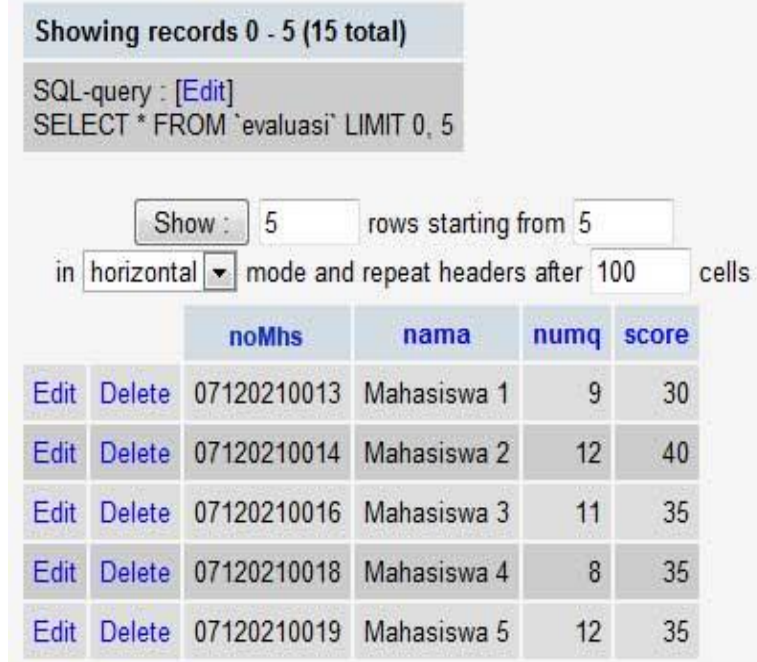

Gambar 7. Isi sebagian tabel dalam basisdata MySQL yang menyimpan data nomor dan nama mahasiswa, jumlah soal yang dikerjakan, dan skor yang diperoleh mahasiswa

Untuk mengatasi kekurangan pada uji coba pertama, dilakukan perbaikan dengan cara memperpanjang durasi timer menjadi 15 menit sehingga mahasiswa memiliki cukup waktu untuk berpikir. Uji coba kedua dengan responden sebanyak 19 mahasiswa memperlihatkan peningkatan pencapaian mahasiswa dalam menyelesaikan soal dengan nilai rata-rata 71.32. Gambar 8 memperlihatkan hasil belajar mahasiswa pada uji coba pertama dan kedua. 

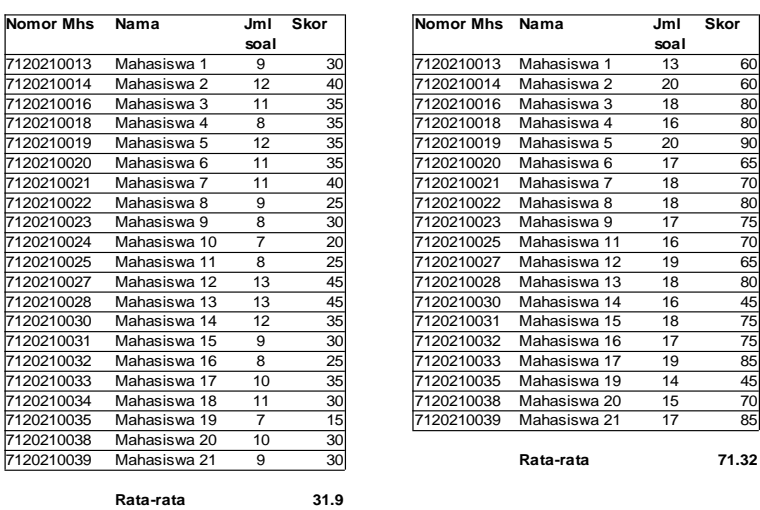

Gambar 8. Hasil belajar mahasiswa pada uji coba pertama (kiiri), dan uji coba kedua (kanan).

\section{KESIMPULAN}

Setelah melakukan pengujian terhadap Flash movie yang dikembangkan, penulis menarik beberapa kesimpulan bahwa:

1. Evaluasi pembelajaran menggunakan komputer berbasis multimedia dapat dibuat dengan Flash sebagai interface atau front-end, dimana pengguna memasukkan data dan mengerjakan soal ujian.

2. Script PHP digunakan untuk menjembatani antara Flash dengan basisdata MySQL, sehingga variabel pada Flash dapat dibaca dan nilainya disimpan ke dalam basisdata MySQL.
3. Aplikasi Flash movie bukan hanya menampilkan animasi, tetapi merupakan aplikasi multimedia yang dapat berhubungan dengan basisdata di server.

\section{DAFTAR PUSTAKA}

1. Capron, H.L., 1996, Computers Tools for an Information Age. New York: Benjamin-Cummings Publishing Company, Inc.

2. Thompson, S., Thurlow, M., and Moore, M., 2003, "Using Computer-based Tests with Students with Disabilities". National Center on Educational Outcomes, Number 15, Diakses dari http://www. cehd.umn.edu/nceo/onlinePubs/Policy15.htm, Tanggal 8 Maret 2007.

3. Anonymous, 2006, SAP Algoritma dan Pemrograman. Tangerang: Sekolah Tinggi Teknik Multimedia Cendekia Abditama.

4. Vaughan, T., 2006, Multimedia Making it Work. Yogyakarta: Penerbit Andi.

5. Luther, A., 1993, Authoring Interactive Multimedia. New York: AP Professional.

6. Sutopo, A.H., 2003, Multimedia Interaktif dengan Flash. Yogyakarta: Graha Ilmu.

7. Sanders, W.B. and Winstanley, M., 2001, Serverside Flas. New York: Hungry Minds. 